\title{
PARA UMA CARTOGRAFIA DA EDUCAÇÃO ESCOLAR INDÍGENA
}

\author{
América Lucia Silva Cesar \\ Arissana Braz Bomfim de Souza \\ Suzane Lima Costa
}

\begin{abstract}
RESUMO: Este artigo pretende informar e discutir questões concernentes ao ensino, pesquisa e políticas linguísticas no âmbito da escola indígena, a partir das ações realizadas pelo Núcleo Local do Observatório da Educação Escolar Indígena do território etnoeducacional Yby Yara, bem como das práticas de linguajamento produzidas no âmbito de outros espaços de atuação dos povos indígenas do Brasil. Numa primeira parte, apresentamos o que é a educação escolar indígena e o papel do professor indígena no sentido de contextualizar a reflexão sobre a complexidade dos discursos de identidade na escola indígena, tendo como foco a "retomada da língua Patxohã", entre os Pataxó. No segundo momento, apresentamos outro exemplo de política linguística, baseado nos exercícios de linguajamentos presentes nos multiletramentos que atravessam as práticas escolares dos povos indígenas do Brasil.
\end{abstract}

PALAVRAS-CHAVES: Povos indígenas. Educação. Políticas linguísticas. Multiletramentos.

ABSTRACT: This article intends to inform and discuss certain issues concerning teaching, research, and linguistic policies in the indigenous school atmosphere, from actions taken by the Local Observatory Center of Indigenous School Education in the ethnoeducational territory of Yby Yara, in addition to practices of language creation produced in other Brazilian indigenous spaces of action. In the first part, we present that which is indigenous school education and the role of the indigenous teacher in the attempt to contextualize reflection about the complexity of discourses odf identity within the indigenous school, having as a focus the "taking back of the Patxohã langauge" among the Pataxó. In the second part, we present another example of linguistic policies, based on the exercises of language creation present in the multiliteracies, that cross over with Brazil's indigenous peoples' school practices.

KEYWORDS: Indigenous peoples. Education. Linguistic policies. Multiliteracies.

\section{INTRODUÇÃO}

Por que os povos indígenas precisam de educação escolar, específica e diferenciada? Afinal, o que é mesmo educação escolar indígena? Não seria melhor apostar na educação formal não-indígena, válida para todos, do que numa educação específica, mas precária? Essas e outras perguntas que circulam, inclusive, no meio acadêmico, são reveladoras do desconhecimento e dos mitos associados à escola indígena, que, em última análise, interpelam a sua pertinência no contexto das políticas 
educacionais no Brasil. Embora o movimento por educação diferenciada, em consonância com interesses e modos de viver das diversas comunidades indígenas, seja um dos mais significativos marcos que se fincam na configuração política do Brasil e no movimento indígena hoje, são, ainda, múltiplas e abundantes as imagens do preconceito, ambiguidades e contradições em relação aos indígenas, principalmente no que se refere à sua organização tradicional e o direito a uma educação diferenciada. Dessa maneira, a educação escolar indígena como objeto de estudo ainda desfruta de pouco espaço acadêmico, principalmente quando se trata de políticas e metodologias de ensino e pesquisa; ainda que existam já algumas iniciativas, relativamente recentes, no sentido de contribuir para o desenvolvimento de estudos e programas de pesquisa nessa área.

Neste artigo pretendemos informar e discutir sobre ensino, pesquisa e políticas linguísticas no âmbito da escola indígena, a partir das ações realizadas pelo Núcleo Local do Observatório da Educação Escolar Indígena do território etnoeducacional Yby Yara. ${ }^{1}$ Esse esforço teórico-metodológico se integra ao trabalho de construção de uma cartografia da educação escolar entre os povos indígenas na Bahia, meta do plano de ação para implantação do território etnoeducacional Yby Yara. Numa primeira parte, apresentamos ligeiramente o que é a educação escolar indígena e o papel do professor indígena no sentido de contextualizar a reflexão sobre a complexidade dos discursos de identidade na escola indígena, tendo como foco a "retomada da língua Patxohã" entre os Pataxó e os multiletramentos que atravessam as práticas escolares. Em seguida, apresentamos outro exemplo de política linguística, baseado nos exercícios de linguajamentos presentes nos multiletramentos que atravessam as práticas escolares dos povos indígenas do Brasil.

\footnotetext{
${ }^{1}$ O Observatório da Educação Escolar Indígena é um programa nos moldes do Observatório da Educação para fortalecer a pesquisa e a formação de professores na área específica da educação escolar indígena. Resulta da parceria entre a Capes com a Secretaria de Educação Continuada, Alfabetização e Diversidade (Secad) e com o Instituto Nacional de Estudos e Pesquisas Educacionais Anísio Teixeira (Inep) do Ministério da Educação (MEC) visando fortalecer a pesquisa e a formação de professores na área específica da educação escolar indígena. Cabe ainda ressaltar que o Projeto Observatório da Educação Escolar Indígena/Núcleo Local do Território Etnoeducacional Yby Yara é uma iniciativa do Programa Pós-Afro/UFBA, em atendimento ao edital 001/2009 da CAPES/SECAD/INEP para implementação do Observatório da Educação Escolar Indígena.
} 
Discutir a educação escolar indígena, a partir do nosso contato com os sujeitos e contexto da pesquisa, é acreditar, junto com Bartolomé Meliá ${ }^{2}$ e outros, que a escola indígena é um campo profícuo para a compreensão dos conflitos e encontros interculturais, das tarefas de uma educação que incorpore a memória e identidade dos povos indígenas como um patrimônio a ser estudado e valorizado não só na escola indígena, mas nas escolas brasileiras como um todo.

\section{O QUE É EDUCAÇÃO ESCOLAR INDÍGENA?}

No que se refere ao nosso pedaço mais próximo, hoje, na Bahia, convivem entre 30 a 35 mil indígenas de mais de quatorze etnias. Esses povos vêm lutando em diversos espaços, para implantar escolas indígenas - são mais de sessenta - e assumir a sua gestão, lutando por uma formação de qualidade dos seus professores, inclusive em nível universitário na graduação e pós-graduação, de modo que garanta pesquisa e prática pedagógica em consonância com os seus projetos societários. De acordo com a definição da Organização das Nações Unidas de 1986,

As comunidades, os povos e as nações indígenas são aqueles que, contando com uma continuidade histórica das sociedades anteriores à invasão e à colonização que foi desenvolvida em seus territórios, consideram a si mesmos distintos de outros setores da Sociedade e estão decididos a conservar, a desenvolver e a transmitir às gerações futuras seus territórios ancestrais e sua identidade étnica, como base de sua existência continuada como povos, em conformidade com seus próprios padrões culturais, as instituições sociais e os sistemas jurídicos. (BANIWA, 2006)

Nesse sentido, a educação diferenciada torna-se condição fundamental para a conservação e proteção do patrimônio cultural, étnico e político das comunidades indígenas e do direito à diferença. São diversas as representações e concepções de escola entre os indígenas, mas é possível encontrar algumas simetrias, dentre elas, a de que a educação escolar indígena é espaço explícito de convivência intercultural: um princípio que está garantido em importantes marcos legais, quando se define a educação escolar indígena como bilíngue e diferenciada.

\footnotetext{
${ }^{2}$ MELIÀ, Bartolomeu. Educação Indígena e Alfabetização. São Paulo, Edições Loyola, 1977.
} 
Ferreira (1992) recompõe a construção da educação escolar indígena no Brasil e elege como ponto de partida a criação da União das Nações Indígenas (UNI), em 19 de abril de 1980. Até aí a educação escolar era fornecida aos índios pelos missionários com fins de catequese, ou pelos órgãos indigenistas como o SPI ou FUNAI. Nesses últimos, prevalecia uma visão integracionista da educação, no sentido da afirmação de um determinado modelo civilizatório, o europeu, em detrimento da diversidade cultural existente entre os povos ameríndios.

Ainda segundo Ferreira (1992), a II Assembléia Indígena do Mato Grosso do Sul, em 1985, proporcionou a formação de grupos para apresentar propostas à Constituinte, e repercutiu na Constituição de 1988. Entre os momentos mais significativos desse movimento por uma escola diferenciada, Côrtes (1998) aponta o Projeto TUCUM, em 1995; a Conferência Ameríndia, em novembro de 1997, que elabora a Carta de Cuiabá; e o jornal da FOIRN $^{3}$, que traça a história da educação escolar indígena no Brasil. Ressalta, ainda, as contribuições dos programas de formação de professores do Acre/Amazonas, Mato Grosso e Minas Gerais que, inclusive, forneceram subsídios para o Programa de Formação dos Professores Indígenas da Bahia, cuja primeira turma constitui-se em 1997.

A partir da Constituição de 1988, as conquistas no âmbito da legislação e dos direitos passaram a garantir uma educação escolar diferenciada e intercultural, bem como uma política educacional que priorize as práticas escolares em língua materna. No entanto, os desafios para assegurar o exercício fecundo desse modelo de escola indígena são muitos e ainda passam pela formação de qualidade de seus agentes, produção de materiais de apoio à prática pedagógica e produção de conhecimentos sintonizados com os seus projetos societários, entre os quais se encontram o domínio da escrita e outras tecnologias, valorização da sua forma de construir o conhecimento, valorização das pedagogias indígenas e a constituição de um ambiente para a pesquisa e documentação dos seus usos linguísticos.

Assim, a educação escolar indígena, que resulta desse movimento de mais de quatro décadas, se configura hoje na criação e movimentação de espaços interculturais, onde se debatem e se constroem conhecimentos e estratégias sociais, a partir do contato

\footnotetext{
${ }^{3}$ A FOIRN (Federação das Organizações Indígenas do Rio Negro) é uma associação civil, sem fins lucrativos, sem vinculação partidária ou religiosa, fundada em 1987, para lutar pela demarcação das terras indígenas na região do rio Negro, estado do Amazonas, promovendo ações na área da saúde, educação e autossustentação.
} 
interétnico, nos quais as práticas educativas se associam às políticas identitárias e culturais próprias de cada povo indígena; movimento contínuo de articulação das práticas escolares às dimensões da vida social.

Nessa construção, o professor indígena é elemento fundamental para que os saberes próprios da comunidade educativa indígena sejam difundidos e incorporados nas práticas da escola, em sua origem, uma instituição exógena. Se for colocado em questão por que só o professor indígena é quem pode atuar nas escolas indígenas, a resposta é simples: somente ele realmente conhece intimamente e desfruta do patrimônio cultural do seu povo, passado de pai para filho através da oralidade e outras práticas sociais. Caso contrário, a escola continuará sendo um instrumento de exclusão de saberes e silenciamento da memória indígena. A participação do professor indígena, dessa forma, garante a especificidade da educação escolar. E um bom exemplo da importância do professor indígena nessa construção encontra-se na produção de material didático específico, que deve ser fruto de uma discussão e produção coletiva do povo. Outros dois fatores que também dependem do protagonismo indígena para a qualidade do ensino específico é a gestão da escola e das práticas pedagógicas; de modo que seja possível traçar currículos, disciplinas, conteúdos, calendários que atendam e estejam de acordo com os interesses e necessidades da comunidade.

Dessa forma, torna-se também uma parte da luta por afirmação da educação diferenciada demonstrar e afirmar a importância do professor indígena e do investimento numa formação docente de qualidade.

\section{O OBSERVATÓRIO DA EDUCAÇÃO ESCOLAR INDÍGENA: NÚCLEO LOCAL YBY YARA}

A proposta do Núcleo Local do Observatório da Educação Escolar Indígena no Território Etnoeducacional Yby Yara $^{4}$ visa, justamente, à inserção dos professores

\footnotetext{
${ }^{4}$ A política de implantação dos Territórios Etnoeducacionais, (TEE) criados pelo Decreto Federal no 6.861, de 27 de maio de 2009, ratifica o regime de colaboração entre o MEC, o estado, os municípios e as universidades para a gestão da educação escolar indígena, buscando uma maior integração entre os responsáveis para desenvolver e organizar as ações, como alternativa mais próxima de um sistema próprio de educação escolar, reivindicado pelos povos indígenas no Brasil. No decreto de sua criação, o Território Etnoeducacional Nordeste 1 abrigava os limites território dos Estados de Alagoas, Bahia e Sergipe . Recentemente, por decisão de lideranças indígenas na Bahia, o Território Etnoeducacional Yby Yara foi definido circunscrevendo os limites territoriais do Estado da Bahia, e redesenhando a proposta anterior
} 
indígenas na produção e disseminação de conhecimentos no âmbito dos programas de graduação e pós-graduação de modo que essas ações possam influir na educação escolar básica promovida pelos povos indígenas. Representa, portanto, um conjunto de ações voltadas para a formação de professores e pesquisadores indígenas, produção de conhecimento intercultural e articulação político-acadêmica, que podem estimular e subsidiar iniciativas educacionais e de pesquisa.

É uma preocupação no Observatório estimular a produção de conhecimento intercultural para elaboração de diretrizes específicas para a educação escolar indígena no território etnoeducacional, investigar a base de dados do INEP e outras fontes (SEC, FUNAI, FUNASA), monitorando-as com estudos de campo no Território Etnoeducacional, para integrar uma cartografia e uma base documental que possam apoiar a elaboração de políticas públicas e a prática dos professores indígenas.

Vale ressaltar que essa experiência no Núcleo do Observatório já evidencia algumas questões mais específicas circunscritas em torno de práticas metodológicas de pesquisa acadêmica e de políticas educacionais e linguísticas. Como base para a cartografia das escolas indígenas da Bahia realiza-se atualmente o diagnóstico e acompanhamento dos diferentes povos indígenas e suas comunidades educativas, através de alguns instrumentos comuns (questionário, entrevistas semiestruturadas, reuniões, conversas, textos escritos e depoimentos orais, fotos e outros registros visuais, além dos relatórios de pesquisa). Atualmente são dez povos articulados à pesquisa, com mais de vinte professores/pesquisadores indígenas, que trabalham nas suas aldeias e participam de cursos de formação, dentre eles, o LICEEI. ${ }^{5}$

No trabalho de campo desenvolvido pelo Observatório, vemos a dimensão, importância e responsabilidade do professor indígena junto ao seu povo. Nos diagnósticos produzidos por dez povos associados à pesquisa, através dos bolsistas de graduação, por exemplo, ratifica-se a importância do protagonismo do professor e gestor indígena, já que escola indígena não funciona sem o apoio e a participação da

de criação dos TEE. Entre as justificativas para essa redefinição estão os laços históricos, políticos e culturais que estabelecem os povos indígenas que habitam o Estado da Bahia, ainda que esses limites sejam mais flexíveis quando se trata das fronteiras étnicas, como,no caso dos Pataxó, que mantêm fortes vínculos identitários com parentes em Minas Gerais.

${ }^{5}$ A Licenciatura Intercultural em Educação Escolar Indígena (LICEEI/UNEB) é um curso de graduação, oferecido atualmente para 108 professores e professoras indígenas, de 10 das 14 etnias existentes no Estado da Bahia, promovido pela Universidade Estadual da Bahia e Ministério da Educação como formação em serviço. 
comunidade. Diferente do não índio, o professor indígena fala a "língua" da comunidade, das crianças, dos jovens e dos adultos que estudam nas escolas, buscando atuar juntamente com as lideranças. Eles são os mediadores, fazem da escola um espaço que liga as crianças aos mais velhos, bem como os conhecimentos do próprio povo com os conhecimentos que vêm de fora.

Com atuação deste profissional, a escola deixa de ser um espaço de negação da diversidade para tornar-se um lugar onde a criança indígena deve se sentir segura, compreendida e respeitada. Durante as visitas realizadas nas escolas Pataxó, por exemplo, muitos foram os relatos que exemplificam e ressaltam a importância do professor indígena na educação diferenciada. Casos como o da professora indígena da escola Kijetxawê, localizada na aldeia Cahy, que juntou todos os esforços e conseguiu encaminhar para aposentadoria um de seus alunos que possuía necessidades especiais; ou de uma professora da escola da Aldeia Guaxuma, que, devido à frequência irregular dos alunos adultos, por trabalharem na "panha do café", fazia visita às suas casas regularmente para repassar as atividades escolares.

No entanto, inúmeras dificuldades se apresentam para o professor indígena, tanto na sua atividade profissional quanto no trabalho de formação de pesquisadores e desenvolvimento de suas pesquisas, dentre eles, é possível enumerar ligeiramente: a distância e isolamento dos professores/pesquisadores nas suas aldeias, consequentemente dificuldade de comunicação e poucos encontros para planejamento e estudo; falta de acesso a bibliotecas, internet e outros fontes; pouca intimidade dos professores em formação com a metodologia científica e os gêneros de escrita exigidos pela pesquisa. Todavia, é nesse contexto que estratégias são construídas no sentido de enfrentar as dificuldades e propor soluções criativas e inovadoras.

\section{UM EXEMPLO DE POLÍTICA LINGUÍSTICA}

E se a ação de lideranças, professores e pesquisadores indígenas desponta como um campo instigante para a pesquisa acadêmica e discussão de políticas de educação linguística, não só para os povos minoritarizados, mas para a educação brasileira de uma maneira mais ampla, ela também se torna mais instigante quando incide sobre os povos 
indígenas da Bahia e do Nordeste em geral, sob os quais ainda recai o peso de uma identidade de "povos sem língua", forjada de fora para dentro.

Com efeito, além da trajetória traumática de contato e conflitos dos povos indígenas na Costa do nordeste brasileiro, ao longo desses 500 anos, que os levou a reconfigurações diversas, o trabalho de antropólogos, linguistas, missionários, indigenistas influenciados pelas teorias forjadas no eixo dos países colonizadores e a política integracionista do Estado brasileiro terminaram por contribuir para as representações desses povos como "aculturados", "misturados", quando não totalmente "sem", sem território, sem língua, sem contrastividade cultural (OLIVEIRA, 1999). Presos a essa circunstância histórica, como veremos a seguir, esses povos vêm construindo respostas, no sentido de afirmar a sua etnicidade e o seu patrimônio linguístico, principalmente no âmbito da luta por uma educação escolar diferenciada, intercultural e multilíngue.

O trabalho autônomo, de pesquisa e ensino, desenvolvido nas escolas indígenas por jovens pesquisadores Pataxó, em torno da revalorização da cultura tradicional e língua Pataxó, é emblemático do esforço de professores/pesquisadores indígenas no sentido de retomar o patrimônio cultural e linguístico tradicional que, de acordo com suas próprias definições, encontra-se na memória dos mais velhos da comunidade e na história que construíram como povo. Desse trabalho, há questões teórico-metodológicas instigantes para a formulação de uma política linguística de autoria Pataxó, exemplar para os outros povos, que sofreram processo de esquecimento ou enfraquecimento dos seus usos linguísticos tradicionais.

O processo, que estamos chamando "retomada da língua", tendo como foco a documentação e pesquisa da língua Patxohã, do povo Pataxó, ajuda a responder uma das perguntas que norteiam a construção da cartografia: que educação linguística interessa aos povos indígenas no território?

Responder a essa pergunta é entender que a formulação de políticas relacionadas à pesquisa e ensino de línguas na escola indígena exige também que se respeite a especificidade de cada povo, suas expectativas e interesses em relação aos seus usos linguísticos, quer se dirijam à manutenção, ampliação e/ou reconstrução das línguas maternas, quer se dirijam ao ensino/aprendizagem do português em sua complexidade 
sociocultural, principalmente no âmbito das comunidades específicas, mas também fora delas.

Nas discussões sobre as realidades sociolinguísticas têm-se problematizado as concepções de língua, língua materna, língua portuguesa e língua indígena, já que são inúmeros os registros que apontam para uma dissimetria entre o que concebem os povos indígenas como língua materna, e outros correlatos, a ponto de se colocar a necessidade de uma redefinição dos conceitos acima referidos, de acordo com a ótica e os interesses dos povos em questão.

\section{POLÍtiCAS LINGUÍSTICAS COMO PRÁTICAS DE LINGUAJAMENTO}

Algumas perspectivas teóricas pós-coloniais ${ }^{6}$ já atentam para a necessidade de repensarmos os tradicionais conceitos de língua, linguagens e seus regimes de saber, para demonstrar como a nossa formação intelectual ainda constrói seus paradigmas a partir dos valores de uma colonização eurocêntrica. Nos estudos pós-coloniais de Walter Mignolo, por exemplo, ao analisar a forma como esses paradigmas se constituíram ao longo da formação do sistema moderno/colonial, discute-se como foi construído um tipo de colonização epistemológica, etnocentrismo nas formas de pensar língua, cultura, literatura, filosofia e outras ciências na América latina.

Em seu livro, Histórias locais, projetos globais, Mignolo produz, a partir da relação entre colonialidade e epistemologia, um estudo genealógico dos processos de silenciamento e subordinação instituídos nas línguas, memórias e saberes dos povos da América Latina, demonstrando como as heranças e os legados coloniais se encontram com os processos de globalização. Configurações que fazem ver o formato dos novos mapas linguísticos transnacionais, nos quais a língua é transfigurada no que o autor chama de novas formas de linguajamento.

\footnotetext{
${ }^{6}$ Vale ressaltar que essas teorias têm bases e fundamentos em movimentos descoloniais que compreendem as ativistas do Fórum Social Mundial, o Zapatismo, o movimento pelos direitos civis nos Estados Unidos na década de 60, a negritude, o movimento indígena na América Latina, na Austrália, Nova Zelândia, os quilombolas e o projeto de pesquisadores negros no Brasil até projetos intelectuais como a Filosofia da Liberação e o projeto da transmodernidade (Dussel), Estudos da Subalternidade do sul asiático (Guha, Spivak, etc). Ver: http://redalyc.uaemex.mx/redalyc/pdf/1591/159114257002.pdf
} 
Cara às teorias mais tradicionais da linguística, a noção de linguajamento, nos estudos pós-coloniais de Walter Mignolo, diz respeito ao pensar entre línguas, rompendo com o monolinguismo colonial e nacional para fazer valer os saberes 'subalternos das línguas sem gramáticas'. Em outras palavras, linguajar é estar entre línguas, independente de termos aprendido uma língua estrangeira, independente também do tipo de código que registra essa língua.

Assim, é possível compreender o linguajar entre línguas como prática afirmativa dos códigos que letraram os povos indígenas ao longo das suas histórias: sons, cores, imagens, números, letras, brinquedos, paisagens, movimentos, memórias... tidos não apenas como gestos físicos da língua literal, descritiva ou ideográfica, mas também na produção dos vários sentidos que o dizer de uma língua possibilita. Os exercícios deste 'pensar entre línguas' estão presentes nos modos como os povos indígenas transformam suas formas de dizer em arte de fazer e legitimam suas identidades de falantes através da narração de suas histórias, redimensionando as noções de língua e linguagem, para cartografar a memória do grupo.

Boa parte dos linguajamentos dos povos indígenas está registrada em áudio, vídeos, em textos escritos, em cartilhas e materiais didáticos que fazem valer a dinâmica intercultural de suas produções linguísticas, através dos usos de escrituras multimodais de autoria dos próprios professores da comunidade ou de autoria coletiva. Ultrapassar as configurações históricas e geopolíticas do ocidentalismo, pautado na colonização epistêmica e subaltenização dos saberes, memórias, culturas dos povos indígenas, é ver no fazer dessas escrituras a formatação de um novo sistema conceitual, que desloca o locus de enunciação dos centros do sistema moderno-colonial para suas margens, para as fronteiras das diferentes histórias locais (MIGNOLO, 2005, p. 302).

O que chamamos de escrituras multimodais de autoria indígena é o conjunto das 'escrições' que incorporam várias modalidades de linguagem. Por outro lado, falar de escrição é dizer das práticas de escrituras movidas a partir dos gestos de escrita que o corpo faz ao riscar a superfície durante os rituais e danças nas aldeias; que a câmera filmadora (ou qualquer outro objeto que 'risque') pode agenciar quando plantada na superfície do ombro dos cineastas indígenas; que o traço dos desenhos feitos pelas crianças promove nos livros didáticos de autoria indígenas; que as vestimentas e o artesanato ganham quando são plasticamente registrados nos cantos e nas histórias dos 
mais velhos. Em outras palavras, o que chamamos de produção multimodal de escrituras também implica dizer da necessidade de ressignificar nossos horizontes políticos e epistemológicos, como intelectuais e como sujeitos históricos, diante das práticas de linguajamento desses povos.

Um tipo de exercício representativo desse movimento no Brasil vem se configurando significativamente nos documentários auto-etnográficos que algumas etnias indígenas produzem nas aldeias, desde 1987. Através do projeto "Vídeo nas aldeias", um acervo, com mais de 70 filmes, cartografa e arquiva a memória indígena, afirmando o movimento histórico das políticas identitárias destes povos no imaginário coletivo local e global. Uma das prioridades desse projeto é oferecer um tipo de formação audiovisual através de oficinas de criação de vídeos desenvolvidas em quatro ‘etapas de letramento': roteirização, captação de imagens, análise crítica do material captado e edição. ${ }^{7}$ Como uma das atividades da ONG Centro de Trabalho Indigenista, coordenado por Vincent Carelli, junto aos índios Nambiquara, o ato de filmar cada povo incorporaria o trabalho com a imagem como instrumento político para disseminar local e globalmente a situação contemporânea dos povos indígenas do Brasil: suas lutas históricas em prol da autonomia, seus direitos, o uso de suas línguas, a história de seu relacionamento com o não-indío, como também seus projetos de futuro.

Em 1997, o lugar de produção desses vídeos passa a ser redimensionado a partir do desejo dos próprios indígenas de recriar imageticamente suas histórias através da realização da primeira oficina de formação, na aldeia Xavante de Sangradouro. Assim, o projeto do Vídeo nas aldeias foi se transformando num centro de produção de vídeos e numa escola de formação audiovisual para povos indígenas. A maior parte dos 70 filmes produzidos é de autoria dos cineastas indígenas que participaram do processo de roteirização, captação de imagens, análise crítica do material captado e edição, o que aqui defendemos como sendo etapas do processo de linguajamento audiovisual.

Chamamos de etapas do linguajamento o processo de construção desses vídeos através da organização de textos verbais com não-verbais que promovem o pensar entre línguas: movimento que aceita tanto as características orais no discurso escrito, quanto

\footnotetext{
7 O projeto "Vídeo nas aldeias" tem um trabalho precursor na área de produção audiovisual indígena no Brasil. O objetivo do projeto foi "apoiar as lutas dos povos indígenas para fortalecer suas identidades e seus patrimônios territoriais e culturais, por meio de recursos audiovisuais e de uma produção compartilhada com os povos indígenas com os quais o vídeo nas aldeias trabalha". Disponível em: http://www.videonasaldeias.org.br/2009/vna.php?p=1
} 
traços da escrita no discurso oral. Essa interpenetração das duas modalidades de produção de textos, utilizada pelos grupos indígenas, nos faz pensar numa das operações que, para Michel de Certeau (1982), define os relatos etnográficos: a passagem da tradução da oralidade para a escritura. Memorar as histórias e os rituais contados pelos mais velhos é o primeiro caminho tomado na direção da montagem dessa escritura. Os roteiros escritos pelos povos indígenas são registros biográficos que nos ajudam a refletir sobre o próprio sujeito da produção audiovisual, fazendo da narrativa imagética em si, bem como dos processos de construção destas narrativas, importantes recursos teóricos e metodológicos para pensar como o jogo dessas imagens performa os lugares identitários de formação destes grupos.

Desta forma, vemos a configuração de um arquivo de relatos de "outridades", registrados como memória identitária dos povos indígenas do Brasil, que articulam de diferentes formas a vontade de narrar a sua história e cultura; assim como também vemos a formatação de exercícios de produção de textos multimodais através das práticas de letramentos, empreendidas em cada uma das etapas da produção desses materiais audiovisuais nas aldeias. Assim, as produções audiovisuais desses povos tornam-se registros que nos ajudam a refletir sobre o sujeito da produção audiovisual, fazendo da narrativa imagética em si, bem como dos processos de construção destas narrativas, importantes materiais teóricos e metodológicos para atender aos pressupostos da escola indígena.

O documentário “Já me transformei em imagem”, produzido por Zezinho Yube, da etnia Huni kuin (Kaxinawá) ${ }^{8}$, é um bom exemplo para entendermos o processo de construção dessas narrativas, bem como para tentar agenciar formas metodológicas de trabalho com esse material, que possam atender aos pressupostos da lei 11.645/08. Produzido na língua dos Huni kuin (língua da família Pano: kaxinawá), o vídeo rememora a história do povo kaxinawá desde o primeiro contato, passando pelo cativeiro nos seringais, até o momento presente dos usos e das apropriações das linguagens audiovisuais nas aldeias. O documentário começa com a reflexão da comunidade da aldeia sobre o que é se transformar em imagem: como se vêem e como

\footnotetext{
${ }^{8}$ Os indígenas Huni kuin (Kaxinawá) habitam a floresta tropical no leste peruano, do pé dos Andes até a fronteira com o Brasil, no Estado do Acre e sul do Amazonas, nas áreas do Alto Juruá e Purus e no Vale do Javari. Disponível em: http://pib.socioambiental.org/pt/povo/kaxinawa/print, acessado em 10 de novembro de 2010.
} 
são vistos e como querem ser vistos. Nessa produção audiovisual, o principal lugar de letramento se monta nas formas de autorrepresentação ${ }^{9}$ dos grupos.

A atividade de memorar torna-se o primeiro lugar do letramento que monta o linguajar coletivo construído na aldeia. Exercício produzido por um coletivo de vozes, que por si só dão sentido às suas narrativas à medida que oralizam sobre suas próprias histórias, bilinguajando o Kaxinawá com português, o português com o português, o Kaxinawá com o Kaxinawá e o portu-Kaxinawá com o mundo. Isso porque cada conceito e signo usados no vídeo para nomear as coisas, não possuem significados por si só, mas através de um sistema identitário de relações de diferenças, que dão sentido aos termos, fazendo valer o direito constitucional de escrever o seu próprio texto, em suas próprias línguas.

Esse é o exercício do pensar entre línguas: embaralhar nas escrituras, as memórias, os mitos, as ficções para fazer valer o retorno da força autoral destes grupos. A autorreflexão dos produtores sobre o seu próprio processo de criação, durante o documentário, nos faz pensar a representação das suas identidades como um trabalho de constante restauração, sempre inacabado da imagem que se tem e da imagem que se quer produzir. Parte das discussões operadas nos vídeos dos indígenas coloca em evidência os formatos da representação narrativa, a interação e a composição dos modos de produção de textos através do uso da imagem.

Se tomarmos cada uma das etapas destas oficinas como espaços de criação de textualidades performáticas, no sentido empreendido por aquilo que Judith Butler (1993) chama de um conjunto de gestualidades que fazem significar o sujeito-autor da produção narrativa montada, seja do ponto de vista psíquico, seja do ponto de vista histórico-social, estaríamos diante de um outro tipo de processo 'multimodal' de letramento que significa o sentido da imagem à medida que supõe uma exposição do sujeito enunciador, o local da sua enunciação e a encenação de situações autobiográficas.

Através da experiência da montagem imagética de si, os indígenas fazem uso social dos vídeos, tomando o espectro eletromagnético, as máquinas e a informação

\footnotetext{
${ }^{9}$ Muitas são as leituras críticas e discussões teóricas contemporâneas sobre os novos formatos narrativos de autorrepresentação das minorias políticas. Leituras e discussões que fazem da "crise da representação" nas ciências humanas tônica conceitual para tentarmos refletir sobre duas problemáticas estéticas que atravessam as produções artísticas nos nossos dias: a autoficção e a escrita pós-etnográfica. Para saber mais sobre esses caminhos teóricos ver: KLINGER. Escritas de si, escritas do outro: o retorno do autor e a virada etnográfica. 2007.
} 
como dimensões da natureza para repensar o papel da linguagem, do conhecimento e da comunicação em nossos tempos. Com a apropriação da linguagem audiovisual e com o trânsito nos saberes linguísticos informatizados, o lugar do indígena assume os contornos de uma paisagem deslocante que convida a uma heterogênese cognitiva e interpretativa, ao permitir que as dicotomias primitivo/moderno, nativo/global, natureza/tecnologia, passado/futuro, possam ser pensadas a partir de outras possibilidades conceituais de configuração (NEGRI; HARDT, 2005 p. 13).

Tomar a produção desses povos como material didático, onde o etno, o tecno e o imagético podem ser lidos como uma multiplicidade de modos de fazer, de atuar socialmente através de categorias comunicativas, é apostar na construção de um tipo de instrumento metodológico que permite às populações indígenas desenvolver estratégias de atuações, frente às denúncias contra violações dos seus direitos, bem como promove articulações de apoio entre os povos.

Estas práticas apropriam-se e reinventam os modelos eurocêntricos de escrita em diferentes momentos e espaços de educação tradicional dos povos indígenas. Assim, vemos a configuração de relatos de "outridades", registrados como memória identitária, articular tanto o lugar do conflito de representação e de negociação, quando os jogos de sentidos que performam os lugares eurocêntricos de pensamento sobre o valor das escrições, para quiçá pensarmos, junto a Mignolo, que a diferença colonial pode ser

o espaço onde as histórias locais que estão inventando e implementando projetos globais encontram aquelas histórias locais que os recebem... A diferença colonial é, finalmente, o local ao mesmo tempo físico e imaginário onde atua a colonialidade do poder, no confronto de duas espécies de histórias locais visíveis em diferentes espaços e tempos do planeta (MIGNOLO, 2003, p. 10).

Letrados com o corpo, com os afetos, com os jogos de sentido do dentro e do fora das suas memórias históricas, fazendo valer o direito constitucional de escrever o seu próprio texto, em suas próprias línguas, vemos como as práticas de linguajamento presente nas produções es(ins)critas dos povos indígenas respondem aos propósitos dos projetos e programas das escolas indígenas: um modelo de educação pronto a atender ao cenário das diversidades culturais, políticas, estéticas e comunicacionais em prol da autonomia dos sujeitos que o praticam.

\section{REFERÊNCIAS}


AUGÉ, Marc. Hacia una antropología de los mundos contemporáneos. Barcelona: Gedisa, 1995.

BANIWA, G. $O$ índio brasileiro: o que você precisa saber sobre os povos indígenas no Brasil de hoje. SECAD/MEC, Brasília, 2006.

BARTHES, Roland. Inéditos, Vol. 1 - Teoria. Trad. Ivoni Benedetti. São Paulo: Martins Fontes, 2004.

CAVALCANTI, M; BORTONI-RICARDO, S. (Orgs.) Transculturalidade, linguagem e educação. Campinas, Mercado de Letras, 2007

GARCIA, Elisa Frühauf. As diversas formas de ser índio. Rio de Janeiro: Arquivo nacional, 2009.

FERNANDES, Florestan. A Função Social da Guerra na Sociedade Tupinambá. 2a ed., São Paulo: Pioneira, 1970.

BUTLER, Judith. Bodies that matter: on the discursive limits of "sex". New York, London: Routledge, 1993.

CANCLINI, Nestor Garcia. Quem fala e em qual lugar: sujeitos simulados e pósconstrutivismo. In: Diferentes, desiguais e desconectados. Trad. Luiz Sérgio Henriques. Rio de Janeiro: UFRJ, 2005.

DELEUZE, Gilles. Gaguejou. In: Crítica e clínica. Trad. Peter pál Pelbart. São Paulo, Ed. 34, 1997.

GEERTZ, Clifford. A interpretação das culturas. Rio de Janeiro: LTC, 1989.

KLINGER, Diana. Escritas de si, escritas do outro: o retorno do autor e a virada etnográfica. Rio de Janeiro: 7Letras, 2007.

KRESS, G.R. and VAN LEEUWEN, T. Multimodal Discourse: the modes and media of contemporary communication. London: Edward Arnold, 2002.

MARTIN-BARBERO, Jesús \& REY, Germán. Dimensões do saber e novos modos de ver/ler. In: Os exercícios do ver: hegemonia audiovisual e ficção televisiva. $2^{\mathrm{a}}$ Ed. São Paulo: Editora SENAC-SP, 2004.

MELIÀ, Bartolomeu. Educação Indígena e Alfabetização. São Paulo, Edições Loyola, 1977.

MIGNOLO, Walter. Histórias locais projetos globais: colonialidade, saberes subalternos e pensamento liminar. Trad. Solange R. de Oliveira. Belo horizonte: Editora UFMG, 2003. 
SOARES, Magda. Letramento: um tema em três gêneros. Belo Horizonte: Autêntica, 1999.

RECEBIDO EM: 01 de novembro de 2012

APROVADO EM: 03 de dezembro de 2012 